\title{
PARA O-CU-PAR, ENTRE! \\ ENTRE POLÍTICAS, ESTÉTICAS, SUBJETIVIDADES E CORPOS INDISCIPLINADOS
}

\section{Paulo César García*}

RESUMO: Considero tratar o ato de ocupar a literatura por um lugar político e como tendência inovadora da estética que agencia possibilidade de discursos que assumem o plano do político-cultural pela experiência de subjetividades, com produções que refletem as potentes formas de existências em criativas e provocadoras escritas que representam a ambiência LGBTTTs. Este texto se fundamenta por trazer à tona as rupturas que envolvem as identificações de gêneros, evitando regras generalizadas que marcam privilégios de termos flexionados no masculino e de formas primárias do binário tocadas pelas referências de sexualidades masculinizadas. A palavra o-CU-p-ação pretende debater o que pode falar sobre a zona do corpo politizada por estéticas, do que traduz pela marca do queer o desejo de existir menos sexualizado e mais fomentado para entreter a inserção dos subalternos/as. A visão de transversalidade é buscada com a noção de comparativismo, para apresentar a leitura crítica ao literário, a partir da crítica cultural em Coutinho (2003), Preciado (2000, 2003, 2014), Butler (2003), Foucault (1988, 2003), Hocquemghem (2000), Ranciére (2005), com o objetivo de operar o sentido do anal como metáfora pensante e politizada e com a qual busco analisar as obras literárias de Marcelino Freire (2003), Bernardo Santareno (2006), Waldo Motta (2008, 1996, 1984) como estéticas críticas que veem as subjetividades e corpos indisciplinados.

PALAVRAS-CHAVE: Corpos indisciplinados; Literatura; Poder anal; Subjetividades.

\section{O-cu-p-ação em espaços da literatura}

Algumas premissas para este texto, a respeito de a Literatura Comparada não visar a uma metodologia cerrada, dizem respeito a como ela se serve de possibilidades analíticas, mostra-se por um processo de questionamentos direcionados às traduções culturais e às linguagens que se fazem presentes no seio social, operando diálogos férteis com o real.

\footnotetext{
* Professor Titular do Curso de Letras e do Programa de Pós-Graduação em Crítica Cultural da Universidade do Estado da Bahia (Uneb), Campus II. Doutor em Literatura (UFSC).
} 
Tânia Carvalhal aponta para o propósito de um eixo transversal do comparativismo que possa inserir leituras críticas que, diz a autora:

\begin{abstract}
Além disso, fica igualmente claro que comparar não é justapor ou sobrepor, mas é, sobretudo, investigar, indagar, formular questões que nos digam não somente sobre os elementos em jogo (o literário, o artístico) mas sobre o que os ampara (o cultural, por extensão, o social). (CARVALHAL, 1991, p. 02).
\end{abstract}

O que se enuncia em torno do termo tradução está ligado à vertente cultural na dimensão do campo discursivo, ao processo de descentralização de significantes e aos meios de se vincular às críticas no estreito jogo artístico com o político. A noção de comparativismo levada a cabo o cenário atual do contemporâneo se quer visada para alcançar outros extratos culturais, de modo a não somente situar posições hegemônicas que englobam a regularidade de enunciados de discursos, mas incorporá-los dentro de contextos em que a relação de poder-saber ou saber-poder atinjam centro versus periférico que, por sua vez, está calcada, também, aos cortes e rasuras, recortes e fissuras, tendo o texto literário o filtro da exterioridade para apresentar modos outros de enunciação. Creio que é por esse lugar que o literário se dispõe pela vertente do ato de comparar, se atrelar, verticalizar os contextos socioculturais como para repensar vozes audíveis e silenciadas, ditas nos interditos e dos interditos elevar a disposição de poder, desbravar operações menos centralizadoras com as tramas do cotidiano, do real da vida e da arte.

Nos termos de Eduardo Coutinho, a transversalidade constitui-se como traço fundamental para o comparatisvismo, tendo em consideração tópicos abundantemente explorados pela literatura comparada e proporcionam recortes dialogáveis com outras áreas do conhecimento, colocando a problematização para além da disciplina. Para o crítico, "a questão da mulher na literatura (Women Studies, Chicano Studies) e a questão da homossexualidade, transexualidade, travestis, lesbianidade (Gay and Lesbian Studies)" (COUTINHO, 2013, p. 55) constituem áreas específicas de estudo que se configuram com rigorosa seleção e preocupação científica, bem como na improvisação de tema ou mitos, que deve ser olhado sempre com desconfiança, gerando os filtros com os quais irão 
desencadear o corpus da interdisciplinaridade, de modo que "a questão da adaptação de uma obra de uma esfera artística ou do conhecimento para outra também deixou de ser vista pela perspectiva binária tradicional, que considerava sempre a segunda como devoradora da primeira e passou a ser encarada como uma outra manifestação, uma tradução criativa da primeira, que com ela dialoga, mantendo a sua singularidade". (COUTINHO, 2013, p. 58)

Parto do princípio de a Literatura Comparada, por esse viés de debate e em seu aporte de discussão, abrir algumas reflexões transversais, portanto, que ficam na esfera do pós-colonial e cuja questão é tratar de incluir discursos menos apostólicos para a representatividade do literário, de modo a dinamizá-la como máquina desejante em que possa aí arremessar as subjetividades LGBTTT' ${ }^{1}$ por escritas que afetam a desreferencialidade dos cêntricos modos de enunciar a outridade. Na fronteira entre hegemonia e subalternidade, o que permite presentificar o espaço literário cabe reportar ao perfil de sujeitos de desejos, habilitá-los nos devires e possiveis meios para poder falar. (ROLNIK, 2008, p. 26)

Se as narrativas de ficção dos últimos decênios pós-guerras do século XX se expõem pelos contextos culturais marcados e por buscarem "alianças [...] com outros grupos sociais e outros campos discursivos, com aqueles - aquilo - que muitas vezes elegemos, à distância, como nossos objetos de interesse intelectual", esses "seriam ímpetos pós-disciplinares fortes" (CUNHA, 1998, p.71). Eneida Leal Cunha considera assim a maneira como enredos do real revelam protagonistas em volta de uma singularidade de expressão de si que se nutre entre a condição disciplinar da existência e a indisciplinar formas de vida.

Em tempos de afloração do pós-colonial, por sua vez, tratar de escritas que perturbam a ordem, revelam posturas ordinárias da masculinidade e constituem discursos que

\footnotetext{
${ }^{1}$ Uso a sigla LGBTTT'Ts (Lésbicas, Gays, Bisexuais, Travestis, transexuais, transgêneros, Simpatizantes e ainda Queers) como instrumento político que direciona para a orientação de gêneros e sexualidades.
} 
reposicionam o lugar do outro é poder falar dos ex-cêntricos, é permitir a abertura de fronteiras que tornam as subjetividades possíveis de serem desconstruídas. E, com isso, para tornar o espaço literário representado mais no plano de ações indisciplinares e menos analisado por um patamar do sistema patriarcal -, revisitando visões heteronormativas como solícitas para entender por onde e como essas vozes se construíram, se constituem e se constroem, como as atuais que não se calam, requisitar a base das identidades sexuais, raciais, de classe e de gênero - é um modo de ver como as evidências balizam os saberes disciplinares, com todo seu caráter reducionista, essencializador e, mesmo, falocêntrico. (PELÚCIO, 2012, p.403).

Lésbicas, gays, bissexuais, transexuais, transgêneros, travestis, simpatizantes, queers enfim, se destacam no movimento ativista no espaço literário, se fazem necessários por abater a grade da intolerância com discussão mais visível e viável e que possam ser o foco de atenção de teóricos/as dos Estudos Literários, não para serem engajados/as na legitimação dos gêneros visualizados para a literatura, porém, "como reconhecidamente importantes” para a (re)posição “dos grupos sociais que elas representavam” (THURLER, 2011, p. 01). Partindo da abordagem literária elencada em obras poéticas e ficcionais, é possível ser pensada por locais de falas, reconhecendo/lendo as referentes representações de temáticas LGBTT'Ts que visem a proporcionar o eixo da transversalização, localizando o instituído e colhendo políticas direcionadas ao plano artístico com as quais corroboram a instaurar a extensão entre o cultural e literário na dimensão de locar as diferenças para o seio cultural.

As leituras que englobam temas sobre as diversidades de gênero e de sexualidades se veem configuradas em espaços de escolas, bibliotecas, livrarias, feiras e festivais literários, eventos acadêmicos, nas ruas, trazendo focos de debates sobre as identidades sexuais, visadas a ser descolonizadas, e cujos saberes e suas ideologias são propositais como forma de revelar o front heterocêntrico e procuras para desarmá-lo. A literatura moderna e contemporânea, a partir dos anos 70 do século XX, apresentou o discursivo mais legível e 
inquietante para esse objetivo, de promover com olhos abertos o reconhecimento de pessoas em diversos gêneros, promovendo discussões sobre as sexualidades diversas. Vistas e lidas pelas lentes de leitores, a estratégia de resistência e de fuga aos estereótipos é ponto nodal para a compreensão do literário por esse lugar de enunciação, pois:

É preciso, no entanto, evitar o reducionismo teórico e político que apenas transforma as margens em um novo centro. O movimento não pode se limitar a inverter as posições, mas, em vez disso, supõe aproveitar o deslocamento para demonstrar o caráter construído do centro - e também das margens! (THURLER, 2011, p. 02).

Parece que o ambiente de confrontação, dada a compreensão de Djalma Thürler, é sentido pelo percurso analítico que opera a literatura, desde a antiguidade, vista como um meio de denúncia. No entanto, não se satisfazia sem notabilizar a inversão de ordens discursivas ou mesmo viabilizar os deslocamentos de sentidos, com críticas ao cânone e aos testemunhos que potencializam leituras mais inovadoras e mais democratizadas com textualidades, obras e autorias literárias. Quero dizer, cabe inserir mesmo o ato de ruptura com a tradição, romper estigmas, disseminar estratégias que logrem pensar a subalternidade como fonte de discurso, sem padronizar o texto por estruturas polarizadas do signo. Se as leituras engajadas não problematizaram enunciados LGBTTT'Ts no passado distante, nem correram o risco de codificá-los e nem os significados das regularidades do heterocêntrico, sem as devidas posições de textos e leitores com as quais tratariam de interpretar juízos e valores da arte filtrada por aqueles enunciados, aferir dos contextos sociais da cultura ocidentalizada a vazão heterossexista e patriarcalista sempre foram movidas a serem refletidas e menos criticada.

Trazendo tais discursos, como politizar identidades e não ofuscar identidades em política no espaço literário, quais relações de poder se calcam, propiciam hierarquias e subordinações de leituras? Que versão da contemporaneidade do final do século XX e do atual XXI fazem dos discursos promessas de quebranças aos códigos que totalizam os referenciais, reproduzem modelos instituídos e também almejam desvelar as interpretações dos seguimentos ordinários que se pautam nos cêntricos motivos de ler e ver o outro? 
São proposições que pautam a agenda do comparativismo e que se comprometem com linguagens que assimilam a historiografia, suscitando em autores e obras silenciados a perspectiva de perscrutar questões identitárias. Certamente, brota o sentimento da onda ideológica já muito consolidada, desde o parâmetro de análise dos contextos sociais para o literário até a direcionar mais ainda o direito à literatura, como preconizado por Antonio Candido (2006), ao buscar um fórum de debates sobre os direitos humanos e com os quais os estudos LGBTTTs se inserem, melhor, são inclusivos nas bases analíticas do literário. Questionar as abordagens universais envergadas pelo feminismo e os jargões tradicionais da heterossexualidade compulsória como busca de rompimentos, a exemplo do que aconteceu com o movimento feminista, são instâncias críticas a serem seguidas, declinando dos páreos do hegemônico e do não-canônico que constituem partes das fronteiras que a literatura vem atuando com grande achado de saber.

Não é à toa que há mais de trinta anos, a teoria do pós-estruturalismo e dos estudos culturais trouxeram uma série de leques para a desconstrução da vida e da cultura nacional, tendo em vista uma tomada de leituras de pesquisadores/as, a partir de considerações interpretativas frente à exposição de imagens, "fantasmas", significados que embaralham e embaralhavam a partilha das identidades em seus diversos modos de enunciação. Embasadas pelas referências epistemológicas da crítica pós-estruturalista e dos estudos culturais, o percurso para a noção de homocultura, princípio que Mário César Lugarinho e José Carlos Barcellos apresentaram para um contexto cultural e histórico da nação, e debatendo a importância de peso para a questão da identidade sexual gay vivenciada e construída no Brasil, fora acolhido, visando o que já havia desatado os nós com a crítica feminista e com a ótica dos estudos sobre a mulher no eixo das análises literárias, a exemplo do que realizavam as Professoras e Pesquisadoras Zahidé Muzart e, mais frequentemente, Tânia Regina Ramos, Simone Schmidt e Cláudia Lima Costa, na Universidade Federal de Santa Catarina ou Ivia Iracema Duarte Alves, na Universidade Federal da Bahia.

Portanto, a literatura não deve ser refutada aos olhos da discriminação no ambiente acadêmico, pois, ao partilhar da noção de Ranciére (2005), que trata a estética o-cu-pa-da 
por políticas vista pela base em competências ou incompetências para o comum, significa exaltar o princípio de como as leituras são construídas e tornam uma possibilidade de exercitá-las com a experimentação de subjetividades fora-do-eixo-comum, em suas diversas formas de fala. Perceber como os outros e novos ex-cêntricos enunciadores são peças fundamentais na história e na memória coletiva de nossa sociedade, avaliando a relevância da presença dos/as que são inomináveis para uns, mas tão vivas pessoas para outros/as, transexuais, travestis, transgêneros, todas com a insistência ao reconhecimento de direitos, de poder, de voz.

A palavra o-cu-p-ação a qual asseguro, aqui, é indisciplinada ao terreno áspero e que visa esgarçar a grafia da palavra que corta e recorta a sílaba tônica, o sentido de cu como potência discursiva, como dinâmica política, em consideração aos saberes de porte descoloniais que se frutificam em domínios outros e aplicados aos lugares mais fluídos e dialógicos. Trata de ver o corpo como dispositivo biopolítico, de modo a se deparar com o poder de mostrá-lo por ruídos no espaço centralizado e acionado na ruptura, no processo de disseminá-lo no jogo da experiência e partilhada pela diferença. A materialização do corpo infame é presentificada pela desnaturalização da biovida, com as marcas de discursos que não produzem a funcionalidade fisiológica e natural, posto que a infâmia atravessa outras fronteiras onde nos faz ver e falar o outro. Quando a literatura visa conceber o lugar por onde o outro fala, num feixe luminoso, capta um poder de nos fazer ver, como diz Deleuze, (1992, p. 134). Ou como propõe Foucault:

[...] faz parte desse grande sistema de coação, através do qual o Ocidente obrigou o cotidiano a se pôr em discurso; mas ele ocupa um lugar particular: obstinado em procurar o cotidiano por baixo dele mesmo, em ultrapassar os limites, em levantar brutal ou insidiosamente os segredos, em deslocar as regras e os códigos, em fazer dizer o inconfessável, ela tenderá, então a se pôr fora da lei ou, ao menos, a ocupar-se do escândalo, da revolta. Mais do que qualquer outra forma de linguagem, ela permanece o discurso da 'infâmia': cabe a ela dizer o mais indizível - o pior, o mais secreto, o mais intolerável, o descarado (FOUCAULT, 2003, p. 221). 
A experiência do infame é a condição sobre a qual nasce à necessidade de refletir o presente no momento em que rompe as idealizações fixadas pelo homem ocidental dos últimos séculos e cuja imagem o refletia a sentir-se seguro com a sua origem e proveniência. O infame é reflexo da relativização da experiência de si que, tomado pela linguagem literária, questiona-se a metafísica da origem absoluta, imagem primeira dos sentimentos e do próprio ser.

Então, o reflexo do fora é um pensar a si, é experimentar conforme os processos de diferenciação (DELEUZE, 1992). Quero assim dizer que o ato de ocupar a literatura pela experiência da infâmia significa traduzir a dessemelhança e os contratextos, à medida do que se vê e do que se pode dizer, sobre o que é visto, de quem tem competência para ver e qualidade para dizer, das propriedades do espaço e dos possíveis do tempo. (RANCIÉRE, 2005, p. 17).

Dado o movimento científico e epistemológico fundado pela literatura comparada e os estudos culturais, o movimento de incitar ou de traduzir as reflexões de alguns autores/as da literatura criam formas de intersecções de linguagens, ficando claro, portanto, que a crítica literária se mantém ativa ao lado e à luz das contingências do cânone. Contudo, cabe resistir às investidas contra-canônicas, de maneira a não esquecermos das gritantes elucidações operadas pelas narrativas ficcionais, como as de Marcelino Freire, a poesia de Waldo Mota ou a dramaturgia do escritor português Bernardo Santareno, que registram os assentados pressupostos para uma ocupação descentralizada e excêntrica.

Em suas respectivas obras desses autores, os amparos à extensão do social e do cultural atravessam os rigores da regularidade das subjetividades e as quebras de valores humanos, situando gays que são mirados por buscar ocupar espaços menos heteronormativos. Isso posto, acusar o ato de o-cu-par como local de pensamento significar expressar a si, significa pôr para fora o estado de o-CU-p-ação, o cu em ação e na inquietação de criar uma estética em revolução, uma poética que cria o agenciamento do cu em movimento 
contra os dogmas e à higienização de conceitos e posturas férteis para ser sujeito des-centralizado.

\section{EstÉTICAS de corpos indisciplinares}

Um modo para se pensar a realidade em corpos indisciplinados tem sido tarefa árdua em tempos de intolerância e conservadorismos. Tratando sobre o queer, talvez, Suely Rolnik dê o giro para a problematização da expressão de estranhamento para o diferente, do que se quer a pessoa tornar-se, do que difere e como se enuncia por renúncias, produzindo diferenças com a heteronorma, colocando assim os sujeitos em crise no

[...] modo de subjetivação dominante, arrastando junto com seu desmoronamento toda a estrutura da família vitoriana em seu apogeu hollywoodiano, esteio do regime que, naquele momento, começa então a perder a hegemonia. Cria-se uma "subjetividade flexível", acompanhada de uma radical experimentação de modos de existência e de criação cultural para implodir no coração do desejo, o modo de vida "burguês", sua política identitária, sua cultura e, evidentemente, sua política de relação com a alteridade (ROLNIK, 2008, p. 30-31).

Ao descolonizar o pensamento sendo possível pela flexibilização de subjetividades, a teórica trata de não perder de vista que o sentido de experimentar modos de existências e suas implosões a um sistema enquadrado está em atividade. O sentido de queer visa despistar, provocar, disputar retóricas de um real calcado, reprodutivo e, muitas vezes, recalcado para a esfera cultural. Próximo da afirmação de Inocência Mata que parte do lugar em que se mostra, o retrato de interditos de nossa linguagem

[...] Decorre desta reflexão a consideração de que porventura a mais importante mudança a assinalar é a atenção à análise das relações de poder, nas diversas áreas da atividade social caracterizada pela diferença: étnica, de raça, de classe, de gênero, de orientação sexual... Neste contexto, julgo que os destinadores das teorias pós-coloniais pretendem que elas funcionem, também, como instrumento de análise de relações de hegemonia e desvelamento da colonialidade do saber segundo uma estratégia de resistência a sistemas de 
conformação da tendência hierarquizante da diferença [...] (MATA, 2014, p.31)

Ao apontar para o que e como nos movem, dentro de uma perspectiva queer, dispor do saber colonizado, de quem está em desconformidade com o mesmo e perceber que os sujeitos descolonizados são dessemelhantes perante às relações assimiláveis aos gêneros impostos e naturalizados, do feminismo que procura construir subjetividades de mulheres menos objetificadas e violentadas física e simbolicamente, de conjugações de raças no jogo do conservadorismo colonial, de exercitar a maneira como o racial é descartado para a classe burguesa e capitalista e em desconsiderar a diversidade sexual negra, gays, transexuais, travestis dos domínios da heterossexualidade cis, faz-se por um mergulho da história dos sujeitos. Assim, Inocência Mata motiva a reposicionar a estrutura política, tomando o seu lugar como mulher e negra.

O duelo norma versus a-normal se constitui e se enuncia com a herança colonial da mais perversa e atuante frente aos princípios que tomam conta da margem, mesmo já desconstruindo os vários lugares de fala. Compartilhar o significado de queer pelo viés analítico do pós-colonial, também, é ponderado por Maria Cecília Santos de que “o problema consiste em repensar (e se praticar) uma política de identidade que não seja essencialista e totalizante, que leve em conta as diferenças internas e externas a uma determinada identidade coletiva" (SANTOS, 1995, p.54). Levo em consideração também o que Walter Mignolo (2008) trata ser contraditório falar de políticas identitárias sem “escorregar” no perigo do essencialismo. Para ele, por que não pensar em identidades em política? pois

[...] a identidade em política, em suma, é a única maneira de pensar descolonialmente (o que significa pensar politicamente em termos e projetos de descolonização). Todas as outras formas de pensar e agir politicamente, ou seja, formas que não são descoloniais, significam permanecer na razão imperial; ou seja, dentro da política imperial de identidades. (MIGNOLO, 2008, p. 290).

Visto que o sentido de identidade em política é uma forma de descolonizar, romper dogmas e racionalidades ditatoriais, tratar da contrariedade à inteligibilidade e à coerência 
entre sexo e gêneros, prática e orientação sexual significa desestabilizar os corpos mais dóceis e entrar em zonas intersticiais que desembarquem de realidades centradas em tempos coléricos para enunciar possibilidades subjetivas de existir. É dentro da postura crítica cultural de gêneros que Paul B. Preciado (2003) retoma a formulação de Tereza De Lauretis para abordar a:

'Desidentificação' (para retomar a formulação de De Lauretis), identificações estratégicas, desvios das tecnologias do corpo e desontologização do sujeito da política sexual são algumas das estratégias políticas das multidões queer. Desidentificação surge das "sapatas" que não são mulheres, das bichas que não são homens, das trans que não são homens nem mulheres. (PRECIADO, 2003, p. 15).

Dentro do campo de sentido do queer, ele está ligado à precariedade de pessoas que não se ajustam à inteligibilidade de gênero e que correm o risco de violências ao serem demarcadas pela patologização e naturalização de corpos. O modo de e como ocupar espaços não é de preenchimento com as pessoas diferenciáveis e diferenciadas pelo sexo, gênero, raça, mas de poder concorrer para a ação de contraposição aos regimes, normas estabelecidas com todos os códigos de manifestações pleiteados pela política de desontologização do sujeito da política sexual, em todas e todos, inclusive as lésbicas, gays, transexuais, travestis, simpatizantes, queers. Daí a primeira constatação previsível com a qual Paul B. Preciado argumenta é como fazer a revolução anal. Para ele, que já passou pela transgenerização de si, do corpo e da subjetividade em movimento, alguns órgãos do corpo gozam de um estatuto biopolítico privilegiado, mas o ânus é considerado como órgão excretor. Como alçá-lo enquanto prática de amor anal? (PRECIADO, 2000, p. 149).

Em Terror anal, Paul B. Preciado realiza a questão frente ao livro El Deseo Homosexual, de Guy Hocquenghem (2000) que revela como a inserção do queer é definida pelo crítico francês. Trata-se, a princípio, de um saber enunciado pelos "ativistas avessos aos fundamentalismos sexistas e heterocentrados que são impregnados da modernidade" (PRECIADO, 2000, p. 150). Em El Deseo Homosexual, Hocquenghem nutre dos discursos em Foucault e Deleuze não como aplicação do que e como pensam sobre as subjetividades 
miradas pelas técnicas que incitam confessar a verdade do sexo e aos silêncios que se colocam para a prática de resistência e produtor de saber crítico sobre si mesmo.

Em O Anti-Édipo, de Deleuze, Hocquenghem (2000), por sua implicação e extensão ideológica ao conhecimento da obra do pensador francês, enuncia-o como crítica ao capitalismo que toma em consideração a sexualidade como motor central de produção e pressuposto de ação de resistência contra a normatização institucional e ação ao regime heterossexual (HOCQUENGHEM, 2000). É por esse contexto que Hocquenghem constrói argumentos que desvela o sujeito de enunciação científica e de porte político. Para ele, o ânus homossexual fala e produz saber sobre si mesmo, sem culpa, vergonha, pavor moral e busca a excursão para a legitimação, sem os degraus que decorram ser o sujeito visto na patologia ou na deficiência do corpo (HOCQUENGHEM, 2000). O anal visto por um canal de ocupação na estética literária se apresenta na operação crítica e política do conhecimento, elevando o corpo ao patamar de formação social, a trans-formar o cultural, sendo, por isso, revolucionário, estando sempre em jogo com os estigmas da masculinidade hegemônica e com os precursores que novelam sentidos paradigmáticos.

O lugar do discurso queer está implicado nos descentramentos, permitindo a palavra criar outros formatos discursivos, sem atar tão somente para as condições de posicionarse o sujeito de sexualidade como diverso e livre, mas para as diferenças entre as identidades homossexuais, lésbicas, transhomens, mulherestrans, travestis, como moldes operandi para poder abarcar o tom das dissidências formas de reconhecer pessoas. A dissidência sexual e de gênero como genealogia política se ocupa para outras margens, surgida da ruptura que orquestra os tons normalizantes heterossexistas e os fluxos do poder que constituem expressão para não somente visar renegar as injúrias para as subjetividades gays, mas todas e todos que assim reproduzem determinados conceitos essencializadores. Assim, o o-cu-par pelo anal excede a injúria, de acordo com Paul B. Preciado (2000), justamente, por não se conter a fala e manifestar, expressar, expor para não compactuar do lugar que reprime atos de violência, criando outros contextos de enunciação e, por sua vez, permitindo possibilidades para legitimar atos abjetos (PRECIADO, 2000, p.159). 
Como não focalizar o livro BaléRalé 18 Improvisos, do escritor brasileiro Marcelino Freire, em especial, o conto Homo Erectus com as devidas referências às questões peculiares em torno dos reflexos culturais que giram para negatividade do desejo entre homens? $\mathrm{O}$ paradigma de que o sujeito é prenúncio de que amar pode de uma forma e não de outra, como dá o cu, o relato ficcional é deslocado por essa tônica de enunciado. Dar o cu, parindo o poder-foder na ficção de Marcelino Freire, parte do agenciamento de uma política de gênero na arte e com a qual o narrador escreve para querer espantar os recalques. Uma forma de estancar o sentido de Homem pela permissividade do corpo por orifícios que não temem e a escrita compactua da ocupação estética. Atuante nas demais obras de Freire, a escrita é vista como prazer, como um passo para gritar e permitir encenações de subjetividades que não se conformam, que emergem o eu estabelecido e submetido, mas rompido ao mesmo tempo, quando esperneia para si o corpo sem o fruto de ser pecado, moralizado, normatizado. Os relatos do autor apresentam o sintoma de discurso por meio de falhas, ausências, impertinências. Sobretudo, são narrativas propositais para compactuar com o dessemelhante, para quem se desloca, quem não age na diversidade e se orienta sexualmente e desidentificando-se em relação ao gênero inteligível.

O escritor pernambucano de Amar é crime e Nossos ossos traduz uma estética como instância política que des-faz a naturalização de corpos dados por suas normalidades e, para tomá-los em consistências de vidas, inventos históricos, visualizam o ato de o-CU-pAÇÃO, a ação de enunciar desejos com o problema da sexualidade e da civilização castradora e neocapitalista. Eis o que instiga o terrorismo anal dentro da ótica de Paul B. Preciado, a regularidade estrita, domesticada, curvada do desejo heterossexual, sem operar o ato anal. (PRECIADO, 2000, p.161)

Para Emerson da Cruz Inácio: “O corpo silenciado não cala nunca: ele é um texto atravessado, trespassado, transpassado, híbrido, uma bioralitura. O corpo colonizado não escreve, reproduz! O Corpo Liberto se retraduz, cria, gesta, gera e se publica! ” (INÁCIO, 2016), e a liberdade de um 'gênero', portanto, é 'foder'. A questão anunciada por Paul B. 
Preciado é como alçar o amor pela prática do cu, problema que gera a personagem João Agonia.

A dramaturgia portuguesa O pecado de João Agonia, de Bernardo Santareno não se furta de expressar a carga dramática, com ação que deixa rastros na figura personagem que se vê envolta da regulação da identidade sexual. O desejo de ter o amado Toino Giesta, este sendo aprisionado pelos conceitos mórbidos de que o cu é excretor, anti-higiênico, revela a história, com todas as castrações culturais do local, gerada pelos diálogos comuns que se arriscam nas falas e que cospem para fora a evidência heteronormativa dos homens que não aceitam a homossexualidade de João. O ciúme de Maria Giesta, ao ver o rosto do irmão talhado na madeira por João Agonia, metaforiza o "fuder" como um pecado, e não correspondido o amor do protagonista, ritualiza a abjeção descrita no relato dentro do contexto da ação biopolítica, registrada na relação heterossexual versus homossexual, no forte recorte do chamado para o másculo e o masculino versus a instância da subjetividade vista como feminina, frágil, emotiva, sensível: “(Riso nervoso) Vai-te daqui, Toino! Corre, foge de mim!! Não me mostres essa cara: sentes nojo? ... tens medo?!... Sai da minha vida, Toino Giesta!!!” (SANTARENO, 2006, p. 146).

O corpo abjeto problematizado no desejo/prática de poder-fuder, do homem afrontando o injuriado, como pensa Butler (2003), também, diz do silenciamento da dramaturgia, com o referencial da cultura local dada a materialidade do cânone português. Isso é visualizado pelo crítico Mario César Lugarinho, quando analisa a obra de Al Berto como o provável ato consequente de afastamento de leituras críticas para o tema em questão, como do próprio espaço literário que não expõe a homossexualidade como relato a ser dito. Afirma Lugarinho, a respeito da literatura portuguesa e da crítica a esta elaborada ser "sempre acadêmica, não ousa identificar a questão problematizante da diferença sexual, preferindo anotar em todos os efeitos estilísticos e formais que a mestria da língua lhes possibilita” (LUGARINHO, 2001, p. 857).

A subversão custa caro para o drama e a agonia de João que paga com a vida o fundamento de não ser projetor de um modelo estabelecido, destravando a relação binária 
para o que, a todo momento, se busca tratar: os tempos de cólera que não cessam. Agredido, violentado verbalmente e tirada a vida pelo pai, o protagonista vai na contramão da heterossexualidade cis, buscando uma alternativa para um corpo possível e com o qual a escrita faz acontecer, provocando conceitos e almejando a expulsão dominadora com ares de evocação abjeta de revelar-se, tal que assume para si o corpo que semeia, escreve, espreita pelo texto que cria no transbordamento de si. Mesmo estando em ambientes centralizadores, não solicita do centro a referência para ser sujeito, mas, frente aos moldes de corpos disciplinares, oculta o que sente, o que é. A linguagem híbrida que atravessa a dramaturgia se coloca no plano "normal" e em vidas anônimas e infames.

Emerson Inácio é recorrente mais uma vez pelo modo como enuncia o discurso literário numa diretriz oposta ao cânone e ao tradicionalismo no gesto de compreensão do outro: "Haveremos de assumir que destextualizamos e dessexualizamos o corpo e o saber; pior por deserotizarmos a História, a Vida, o Corpo, transformamos o texto estético, a Literatura na assepsia da vida burguesa. A Literatura-Bovary não se sustenta mais. Precisamos de Literatura-Frankenstein” (2016). Ainda conforme a leitura de Inácio, agregar o signo "Cuir" pode "ser um procedimento estÉtico capaz de associar os diversos campos do saber e do poder em torno de uma possível expressão estética, literária, que corresponda às práticas de ruptura e transgressão" (INÁCIO, 2016).

Portanto, a obra de Santareno, com todo o pertinente modo de falar, desfaz, desarranja a padronização dos espaços canônicos literários numa possível onda de críticas à criação e recepção de textos artísticos, quando não nomeia corpos semelhantes ao sistema reprodutor e heteronormativo. O autor naturaliza o corpo de Agonia e, pelos diferentes modos de existir, talvez assim, trate de refletir a história da personagem atravessada por barreiras, traços de corpos envergados, compondo outros corpos numa dinâmica constante

\footnotetext{
2 Termo usado por Inácio e com o qual utilizo nesta análise. A grafia cuir é aportuguesada, quem sabe, para mostrar o estranhamento em que o significado acusa no grau de sentidos que opera dentro do contexto social e cultural brasileiros. Contudo, vejo como uma apropriação para uma subjetividade manifestada pela ótica abjeta, sobretudo, para desmascarar óticas de gêneros e de identidades sexuais possíveis.
} 
para refletir a desterritorialidade, as fronteiras e singularidade de auto-referências de si, sujeitos inusitados, a exemplo da " heterogênese"3.

A linha de fuga que importa a ação de o-cu-par sobrevém com o de presenciar o corpo em movimento, na fluidez da subjetividade conectada a um procedimento político e desidentitário que nos liberte e enfrente os afrontamentos. Como acesso à hibridização que a literatura de Santareno produz, ela instaura uma base estÉTICA ${ }^{4}$ favorável às heterotopias, aos discursos que desarrumam a unicidade de sentidos e desprendem de compartimentações disciplinadas. Assim tomada, uma estética, em volta aos entre-lugares, dialoga com a carnavalização, funda outros meios discursivos com os quais há as possibilidades de outras subjetivações que visam serem distantes das submissões e dos domínios hierárquicos. Por isso, o argumento de Inácio é favorável ao espaço sem-medo de posturas traumáticas do sistema regente da cultura ocidental: "Em lugar de 'Gênero é poder', de 'gênero é poder', a liberdade de um 'gênero é foder': plantar, semear e fazer nascer o corpo que se escreve, um corpo que escreve, que é antes de tudo texto e escrita”. (INÁCIO, 2016).

Ao refletir a desnaturalização do corpo escrito na instância da arte, no gesto insistente para a não-fixidez da identidade de gênero, uma forma, portanto, de incorporar atos de costurar a si no gesto político, é desatar o destaque da refazenda de fios que desfazem a linhagem do discurso único, centralizador, para poder se pôr, poder ser sujeito outro, na alternativa para falar de si pela abjet-ação, na ação de abjetar-se como modo de liberar das impressões im-postas.

\section{Politicus indisciplinados}

\footnotetext{
${ }^{3}$ A partir dos processos intermitentes de desterritorializações e reterritorializações, Deleuze e Guattari desenvolveram a noção de heterogênese, para afirmar que é através dela que se produz algo novo e inusitado para nossas vidas. As linhas de fuga, por sua vez, são similares ao processo da heterogênese. Estão inseridas na ideia de que é possível desfazer-se de um território existencial e criar outros simultaneamente. (DELEUZE; GUATTARI, 1997, p. 158)

${ }^{4} \mathrm{O}$ termo, em destaque, estÉTICA é consoante no destaque em maiúscula como forma de desarticular o instituído para a arte, criando um espaço multicor e menos preciso, quando a alteridade toma eco. Foucault pode aqui ser o referencial, quando trata da estética da existência.
} 
Gayatri Spivak (2010), ao falar de subalternidade, não se refere apenas a um sinônimo para oprimidos ou para os "outros". Os/as subalternos/as são sujeitos e grupos sem autonomia, submetidos/as a outro grupo social, não possuindo posição própria, legítima e se distanciando de uma posição hegemônica; são aqueles/as que não conseguem um espaço em uma sociedade totalitária e excludente. Spivak se volta para questionamentos que visam interrogar fundamentos europeizados que recaem sobre sujeitos subalternos/as dos territórios coloniais, denunciando que, embora o colonialismo tenha ficado "politicamente" no passado, ainda no contexto pós-colonial, pode-se perceber discursos atrelados a uma mentalidade colonizadora; discursos esses construídos através de relações de poder, nas quais a autonomia opressora do "dominante" tende a inferiorizar o sujeito colocado como subalterno. Trazendo essa abordagem para o contexto da construção de identidades sexuais, pode-se entender o sujeito colonial mergulhado a representação do homossexual, que se priva de fala, que se coloca na posição do outro, em detrimento ao contexto opressor que silencia a sua voz, por não encontrar um lugar de enunciação, por não dispor de uma possibilidade de mostrar a identidade gay sem que seja rechaçada pela sociedade.

Spivak apresenta $\mathrm{o} / \mathrm{a}$ subalterno/a como $\mathrm{o} / \mathrm{a}$ "Outro/a", aquele/a posto/a à margem, renegado/a, visto/a como anormal, porém, algumas leituras se apropriam do lugar subalterno de maneira favorável, já que se utilizam do "estranhamento" como ferramenta de enunciação discursiva, trazendo o status de negação como algo pertinente para a sua luta, enquanto outras inferências ao termo aderem-se aos discursos que, por vezes, reforçam a noção do modelo heterossexual como centro de poder. Uma maneira positiva para nomear, instaurar uma perspectiva que vai de encontro às normas socialmente aceitas. Portanto, "falar de saberes subalternos não é, portanto, apenas dar voz àquelas e àqueles que foram privados de voz. Mais do que isso, é participar do esforço para prover outra gramática, outra epistemologia, outras referências que não aquelas que aprendemos a ver como as 'verdadeiras' e, até mesmo, as únicas dignas de serem aprendidas e respeitadas". (PELÚCIO, 2012, p. 399). 
Paul B. Preciado ativa a questão ao retratar sobre o "escuro objeto do desejo" (PRECIADO, 2000), quando gays, lésbicas veem-se na inserção de modelos instituídos pela heteronormatividade e posições fixadas para serem inclusas em direitos societários e culturais.

Quanto aos movimentos de liberação gays e lésbicos, uma vez que seu objetivo é a obtenção da igualdade de direitos e que se utilizam, para isso, de concepções fixas de identidade sexual, contribuem para a normalização e a integração dos gays e das lésbicas na cultura heterossexual dominante, favorecendo políticas familiares, tais como a reivindicação do direito ao casamento, à adoção e à transmissão do patrimônio. É contra esse essencialismo e essa normalização da identidade homossexual que as minorias gays, lésbicas, transexuais e transgêneros têm reagido. (PRECIADO, 2003, p,17)

Judith Butler nota que a heterossexualidade pressuposta nas relações de gênero é opressora, na medida em que busca criar uma unidade e uma estabilidade entre sexo, gênero e desejo. (MARIANO, 2005, p. 487).

\begin{abstract}
Mesmo no campo da sexualidade inteligível, descobrimos que os pólos binários que ancoram suas operações possibilitam zonas intermediárias e formações híbridas, sugerindo que a relação binária não exaure o campo em questão. De fato, existem zonas intermediárias - regiões híbridas de legitimidade e ilegitimidade - que não têm nomes claros e onde a própria nominação entra em crise produzida pelas fronteiras variáveis, algumas vezes violentas, das práticas legitimadoras que entram em contato desconfortável e, às vezes, conflituoso, umas com as outras. Esses não são lugares bem delimitados onde alguém pode escolher passar o tempo ou optar por ocupar posições de sujeito. (BUTLER, 2003, p. 229).
\end{abstract}

A prática legitimadora do discurso literário entra em confronto na poesia de Waldo Motta que ignora a delimitação de ocupar pela oposição, representada pela posição tradicional do sujeito, para estabelecer o lugar do masculino e do feminino. No entanto, as palavras que o poeta interseciona na esfera do poético jogam com as polaridades em direção para refletir a materialidade do corpo, como natural e, sobretudo, retirando dela a pecha de sua normalização imputada quando fala de desejos entre os iguais. Em Bundo e outros poemas, publicado em 1996, o poeta apresenta os resquícios que a natureza assegura, vendo o corpo 
como lugar sagrado, talvez, conveniente para uma época em que os estudos queer não se faziam presentes no Brasil. Contudo, a escrita estética de Waldo Motta remete à oposição e à estrutura estável do sublime como método de representar a poesia que fala da sexualidade por um patamar reconhecido e, ao mesmo tempo, agressivo e contestável para quem e como não visa aos prazeres da carne fora dos contextos da dominação da masculinidade hegemônica. E diz: “aprendi que o corpo é o templo do Pai, do Filho e do Espírito Santo, e de todos os deuses, sendo a própria sede do Reino dos Céus. Assim percebi o quanto certas religiões escondem para impedir a experiência direta e total com o Deus Vivo". (MOT'TA, 2011, p. 3-4)

A trajetória do escritor de Transpaixão produz um deslizamento entre a noção de religar a parte do traseiro como oferta ao prazer, uma produção de vida que retira dos escritos sagrados e constitui daí o significado do conhecimento de que o cu é a zona de atração, apropriação, queerização (PRECIADO, 2015). Não visualiza o cu como demarcado por alarmes noturnos em que o corpo é girado pela poluição arquetípica ligada à sujeira, excrementos, nojo. O uso de poder em sentir o cu se alarga sem repressão e condenação. Por isso, a metodologia encontrada para externar a diferenciação em posicionar a prática sexual como lugar sagrado e político, afirmando assim que:

Não sendo o ânus um órgão sexual, nem sendo elemento anatômico
diferenciador dos gêneros sexuais, pois todos o têm, e pelas costas
todos são iguais, para mim o erotismo anal não pode ser considerado
como ato sexual, mas é indiscutivelmente um ato erótico, sendo,
além disso, e antes de tudo, um ato religioso, visto que o religare pode
ser entendido como ligar pela ré, por detrás, pelas costas. (MOTTA,
2011, p. 2)

Portanto, o poema Pelo rabo é a expressão do religare, ligando o coito não somente ao desejo corporal, mas como conexão ou intermediação das possibilidades de existir, desdobrando a experiência e o agenciamento da subjetividade por lugares mais fluidos. Assim, fala Roberto Schwarz que sua poesia 
[...] toma o ânus do poeta como centro do universo simbólico. A partir daí mobiliza bastante leitura bíblica, disposição herética, leitura dos modernistas, capacidade de formulação, talento retórico e fúria social. O ponto de vista e a bibliografia fogem ao usual, mas o tratamento da opressão social, racial e sexual não tem nada de exótico. (SCHWARZ APUD CORADELLO, 2011, p. 2)

A poesia de Waldo Motta planta e suplanta, coordena eixos libertadores, revela-se no culto político de prezar o cu, portanto, uma forma de ser, de pregar o existir para além de uma moralização dominante e exortadora da masculinidade Páter-família.

PELO RABO

PELO RABO

FISGUEI

O LEVIATEN

$\mathrm{NO} \mathrm{CU}$

DE EXU

A LUZ

(MOTTA, 2008, p. 80)

Por isso, o poeta se identifica Pelo rabo: "Eu não vim trazer a paz, mas a guerra" (MOTTA, 1984), disseminando a rebeldia aos tramites de conceitos normatizados de sistema cultural que reproduz e incita o universo de reconhecimento do mesmo. E diz: "minha poesia é a expressão do inefável, e que o nobre e agradável para Deus é o reles e execrável para a visão mundana” (MOTTA, 2011, p. 3). Se, conforme o poeta, “a saída é para dentro", externar o ânus como rota de descobrimento, visualiza a poesia na construção do performático (BUTLER, 2003), na força política da estética, na citação do sagrado menos sacralizado e mais descontextualizado, procurando inverter posições de enunciados hegemônicos, o que incita o eu a falar. A abjeção, tal como refere Butler (2003) e tratada na poesia de Waldo Motta é contestadora e constitutiva para pensar, debater a identidade indisciplinada, fora do conjunto da heteronormatividade. O corpo-homem tem um rabo e se quer na sanção de possuir seus direitos fora da coerência do sistema sexo-gênero. Para Paul B. Preciado (2015, p. 29), “a identidade de gênero não é a expressão instintiva da 
verdade pré-discursiva da carne, e sim um efeito de reinscrição das práticas de gênero no corpo". (PRECIADO, 2015, p. 29)

\author{
CLARO, CLARO \\ CLARO, CLARO: \\ É PELO TALO \\ QUE COMEÇA \\ O FRUTO. \\ A VIDA \\ MEDRA \\ DO RABO.
}

(MOTTA, 2008, p. 81)

Fica claro para Waldo Motta que a subjetividade não se afunda pelos excrementos e sim por desenvolver a estética do existir pelo abjeto e que, oriundo do rabo, de acordo com a poesia, evoca-se o eu como o ser des-situado, desatado do fruto do talo. O poeta desmistifica a vida sacralizada pelo lugar da potência do falo, e a representa pelo cu, feita a a-normas, a desreferencializar posturas e operações binárias.

$$
\begin{aligned}
& \text { Ó Deus serpentecostal } \\
& \text { que habitais os montes gêmeos } \\
& \text { e fizeste do meu cu, } \\
& \text { o trono do vosso reino, } \\
& \text { santo, santo, santo espírito } \\
& \text { que, em amor, nos forjais [...]” } \\
& \text { (MOTTA, 1996, p. 45) }
\end{aligned}
$$

Por isso, entre políticas, estéticas, subjetividades e corpos indisciplinados, somos conduzidos a revisitar os fios que descosem outros signos, outras paragens, outras realidades, na intenção de a vida ser reconstruída ou reinscrita na prática do gênero, no corpo ironizando o cultural e forjando o pensar, porque o-cu-par as estéticas literárias, é fazer estender, dispersar outros e demais modos de saber, saber-se outro, poder falar. 
ABSTRACT: I consider dealing with the act of occupying literature by a political place and as an innovative tendency of aesthetics that agency possibility of discourses that assume the political-cultural plane by the experience of subjectivities, with productions that reflect the powerful forms of existences in creative and provocative writings which represent the LGBT'T'Ts ambience. This text is based on bringing to light the ruptures that involve the identifications of genres, avoiding generalized rules that mark privileges of terms inflected in masculine and of primary forms of the binary touched by the references of masculinized sexualities. The word o-CU-p-action aims to discuss what can speak about the body zone politicized by aesthetics, which translates by the mark of the queer the desire to exist less sexualized and more encouraged to entertain the insertion of the subordinates. The vision of transversality is sought with the notion of compartivism, to present the critical reading to the literary, from the cultural critique in Coutinho (2003), Preciado (2000, 2003, 2014), Butler (2003), Foucault (1988, 2003), Hocquemghem (2000), Ranciére (2005), with the objective of operating the anal sense as a thinking and politicized metaphor and with which I seek to analyze the literary works of Marcelino Freire (2003), Bernardo Santareno (2006), Waldo Motta (2008, 1996, 1984) as critical aesthetics that see undisciplined bodies and subjectivities.

KEYWORDS: Anal power; Literature; Undisciplined bodies; Subjectivities

\section{REFERÊNCIAS}

BUTLER, Judith. Problemas de gênero: feminismo e subversão da identidade. Rio de Janeiro: Civilização Brasileira, 2003.

CANDIDO, Antonio. Literatura e cultura de 1900 a 1945. In: Literatura e sociedade. Rio de Janeiro: Ouro sobre Azul, 2006.

CARVALHAL, Tânia. Literatura comparada: a estratégia interdisciplinar. In: Revista Brasileira de Literatura Comparada, Niterói, n. 1, mar. 1991.

COUTINHO, Eduardo. Literatura comparada reflexões. São Paulo: Annablume, 2013.

CUNHA, Eneida Leal. Literatura comparada e Estudos culturais. In: BITTENCOURT, Gilda Neves; MARQUES, Reinaldo (orgs). Limiares críticos: ensaios sobre literatura comparada. Belo Horizonte: Autêntica, 1998.

FREIRE, Marcelino. BaléRalé 18 Improvisos. Cotia/SP: Ateliê Editorial, 2003.

FOUCAULT, Michel. História da sexualidade I: a vontade do saber. Tradução de Roberto Machado. Rio de Janeiro: Graal, 1988.

. A vida dos homens infames. In: Ditos e escritos IV Estratégia, poder-saber. Organização, seleção de textos e revisão técnica de Manoel Barros da Motta; tradução de Vera Lúcia Avellar Ribeiro. Rio de Janeiro: Forense Universitária, 2003.

HOCQUEMGHEM, Guy. El Deseo Homosexual. Prólogo de René Schérer. Madrid: Melu$\operatorname{sina}, 2000$. 
INACIO, Emerson da Cruz. Manifesto para uma crítica poética de uma possível existência do corpo na diferença. Erotização da política e a política do desejo: narrativas de gênero e sexualidades em tempos de cólera. Salvador, 2016

LUGARINHO, Mário César. Dizer o homoerotismo: Al Berto, poeta queer. Lélia ParreiraDuarte et al, orgs. Encontros prodigiosos. Belo Horizonte: Editora da UFMG / PUC-Minas, 2001, p. 852-863.

MATA, Inocência. Estudos pós-coloniais: Desconstruindo genealogias eurocêntricas. Dossiê Diálogos do Sul, Porto Alegre: Civitas, vol. 14, n. 1, p. 27-42, jan-abr, 2014.

MIGNOLO, Walter D. Desobediência Epistêmica: a opção descolonial e o significado de identidade em política. Cadernos de Letras da UFF - Dossiê: Literatura, lingua e identidade, Rio de Janeiro, no34, p. 287-324, 2008.

MOTTA, Waldo. Salário da loucura. Vitória/ES: Mimeo, 1984.

Bundo e outros poemas. Campinas: Editora da Unicamp, 1996.

Transpaixão. Vitória/ES: EDUFES, 2008.

O gozo poético do libertino das palavras. Entrevista concedida a Mara Coradello. In: CORADELLO, Mara. Vitória/ES: Revista Cultura Anal, 2011, 2-22 p..

SANTARENO, Bernardo. O pecado de João Agonia. Lisboa: Editorial Nova Ática, 2006.

SANTOS, Maria Cecília Mac Dowel dos. Quem pode falar, onde e como? uma conversa "não inocente" com Donna Haraway. Cadernos pagu (5), Campinas/SP, 1995: pp. 43-72.

SPIVAK, Gayatri Chakravorty. Pode o subalterno falar? 1. ed. Tradução: Sandra Regina Goulart Almeida, Marcos Pereira Feitosa, André Pereira. Belo Horizonte: Editora da UFMG, 2010.

PELÚCIO, Larissa. Subalterno quem, cara pálida? Apontamentos às margens sobre póscolonialismos, feminismos e estudos queer. Dossiê Saberes subalternos. Revista de Sociologia da UFSCar. São Carlos, v. 2, n. 2, jul-dez 2012, pp. 395-418.

PRECIADO, Paul B. Terror anal: apuntes sobre los primeiros días de la revolucíon sexual. In: HOCQUEMGHEM, Guy. El Deseo Homosexual. Prólogo de René Schérer. Madrid: Melusina, 2000.

2003.

. Multidões queer: notas para uma política dos "anormais". In: revista Multitudes, . Manifesto contrassexual. Práticas subversivas de identidade sexual. Tradução de Maria Paula Gurgel Ribeiro. São Paulo: n-1 edições, 2014.

RANCIÈRE, Jacques. A partilha do sensivel: estética e política. São Paulo: Editora 34, 2005. 
ROLNIK, Suely. Geopolítica da cafetinagem. In: Fažendo Rizoma: pensamentos contemporâneos. São Paulo: hedra, 2008, p.25 - 44.

THURLER, Djalma. Masculinidade precária. In: Revistas de Artes e Humanidades, n. 08, 2011.

Recebido em: 23/09/2017.

Aprovado em: 08/12/2017. 